\title{
К ВОПРОСУ О ФОРМЕ ГРАЖДАНСКО-ПРАВОВОГО ДОГОВОРА В УСЛОВИЯХ ЭЛЕКТРОННОГО ВЗАИМОДЕЙСТВИЯ СТОРОН
}

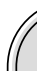

\section{ON THE QUESTION OF THE FORM} OF A CIVIL LAW CONTRACT IN THE CONDITIONS OF ELECTRONIC INTERACTION OF THE PARTIES

\section{A. Barinov \\ N. Kuznetsova O. Ryabova}

Summary. The article is devoted to the consideration of certain issues arising in the application of civil legislation regulating the requirements for the form of the contract when it is concluded during electronic correspondence using the information and telecommunications network "Internet". The analysis of scientific literature and judicial practice shows an ambiguous approach in determining the signs that allow us to talk about compliance with the written form of the contract during electronic interaction of the parties. The conclusion is formulated that the contract should be considered concluded in writing only in the case of an exchange of electronic documents signed with an electronic signature or its equivalent. If electronic documents originating from the parties do not contain an electronic or other signature, they should be considered as electronic messages, which, along with other evidence, may indicate the conclusion of an oral contract.
\end{abstract}

Keywords: form of contract, written form, oral form, electronic document, electronic signature, electronic correspondence, electronic messages.

\author{
Баринов Андрей Викторович \\ К.ю.н., дочент, ФКОУ ВО «Владимирский \\ юридический институт ФСИН России» \\ barinov-vlad@inbox.ru \\ Кузнецова Наталья Владимировна \\ Старший преподаватель, ФКОУ ВО «Владимирский \\ юридический институт ФСИН России» \\ kuznezova-1963@mail.ru \\ Рябова Ольга Алексеевна \\ Преподаватель, ФКОУ ВО «Владимирский \\ юридический институт ФСИН России» \\ frau.lelya2012@yandex.ru
}

Аннотация. Статья посвящена рассмотрению отдельных вопросов, возникающих при применении гражданского законодательства, регулирующего требования к форме договора при его заключении в ходе электронной переписки с использованием информационно-телекоммуникационной сети «Интернет». Анализ научной литературы и судебной практики показывает неоднозначный подход в определении признаков, позволяющих говорить о соблюдении письменной формы договора при электронном взаимодействии сторон. Сформулирован вывод о том, что договор должен считаться заключенным в письменной форме только в случае обмена электронными документами, подписанными электронной подписью или ее аналогом. При отсутствии в электронных документах, исходящих от сторон, электронной или иной подписи, их следует рассматривать как электронные сообщения, которые наряду с другими доказательствами могут свидетельствовать о заключении устного договора.

Ключевые слова: форма договора, письменная форма, устная форма, электронный документ, электронная подпись, электронная переписка, электронное сообщение.

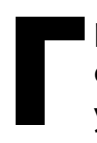

ражданско-правовой договор является универсальной правовой конструкцией, позволяющей удовлетворять потребности любых субъектов гражданского права, связанных с оборотом товаров, работ, услуг, финансовых средств, объектов интеллектуальной собственности. Развитие информационных технологий привело к расширению опосредованных отношений между гражданами в сети «Интернет», с использованием социальных сетей, мобильных приложений передачи сообщений и видео (мессенджеры - WhatsApp, Viber, Telegram и др.), что оказало существенное влияние и на юридическую сторону взаимоотношений субъектов при заключении и исполнении гражданско-правового договора.
Однако, анализ судебной практики показывает, что не всегда достигнутое между сторонами соглашение, лежащее в основе договора, позволяет достичь того правого результата, на который направлено их совместное волеизъявление. В частности, это связано с дефектом внешнего выражения взаимного волеизъявления сторон, объективно доступное для восприятия, которое еще в советском праве определено как форма договора [1, с. 464]. Исходя из законодательного положения, что договор может быть заключен в любой форме, предусмотренной для совершения сделок (п. 1 ст. 434 ГК РФ), в современной юридической литературе большое внимание уделяют исследованию формы сделок [2-10]. Причем анализ формы сделок, в указанных 
работах, основывается на анализе договорных конструкций, не проводя различия между формой сделки и формой договора, что вносит некоторую путаницу в соотношении понятий «форма сделки» и «форма договора», и в свою очередь приводит к трудностям при решении вопроса о том, можно ли считать договор заключенным.

Договор, заключенный в письменной форме не представляет трудностей при разрешении спорной ситуации, возникшей между его сторонами, так как волеизъявление субъектов объективируется в письменном документе. Проанализировав такой документ, суд может установить, как предмет договора, указывающий на вид обязательства, другие существенные условия, исходя из буквального значения содержащихся в нем слов и выражений, так и выяснить действительную общую волю сторон с учетом цели договора (ст. 431 ГК РФ). К достоинствам письменной формы, можно отнести, и выделенную в литературе ее доказательственную, консультативную, информативную и особенно контрольную функцию [9]. Последняя, «облегчает осуществление контроля за законностью совершаемых сделок» [11, с. 164]. Поэтому, при разрешении спора, вытекающего из письменного договора суд должен проверить его соответствие закону и в отдельных случаях по своей инициативе применить последствия недействительности ничтожной сделки (п. 4 ст. 166 ГК РФ).

Перечисленные выше функции письменной формы договора утрачиваются при заключении устного договора, что не позволяет окружающим и суду определенно установить, как предмет, так и иные условия достигнутого соглашения. Так, в судебной практике при отсутствии между сторонами письменной формы договора, в одних случаях суд не может определить однозначно существенные условия сделки, которые стороны имели в виду при вступлении в спорные правоотношения [12, 13], в других стороны не смогли доказать наличие договорных отношений [14-17], поэтому суды признавали договор незаключенным. Это обусловлено тем, что как правильно заметила Е.Н. Абрамова, буквальное толкование названных положений ГК РФ о форме сделок (ст. ст. 158-160 ГК РФ) приводит к выводу, что сделка бывает только одной формы - письменной, а устные сделки совершаются без какой-либо формы [2]. Такой вывод основан на том, что форма должна устанавливать определенные требования, границы, рамки в виде минимума и максимума необходимой формализации содержания сделки, выражения вовне внутренней воли сторон, но у устной формы сделки эти внешние рамки отсутствуют, так что форма такой сделки не определена [2]. Следует отметить, что определение формы сделки через способ, посредством которого участники сделки изъявляют свою волю при ее совершении (устно, письменно, конклюдентными действиями, молчанием), является господствующим в юридической литературе как советского, так и современного периода [10, с. 90; 18 , с. $55 ; 19$, с. 28]. Однако в доктрине гражданского права по-прежнему остаются проблемными вопросы о том, являются ли конклюдентные действия и молчание самостоятельными способами волеизъявления (формами сделки) или разновидностями устной формы и можно ли перечисленные волеизъявления назвать формами сделки вообще.

Решение данных вопросов имеет больше теоретическое, нежели практическое значение. В правоприменительном плане определяющее значение имеет философский подход, рассматривающий взаимосвязь формы с категорией «содержание», что действует применительно и к форме сделки. Так что, познать содержание сделки, направленность ее на достижение определенного правового результата, возможно только ознакомившись с ее формой, внешним выражением волеизъявлением ее участника. Взаимосвязь формы и содержания по-разному проявляется в зависимости от вида сделок: односторонних или двусторонних (договоров). Так, при совершении односторонней сделки, их содержание (волеизъявление) может быть воспринято окружающими, если они совершены устно, письменно, конклюдентными действиями или молчанием. Что касается договора, то его заключение состоит в достижении между сторонами соглашения путем встречно направленных и взаимно согласованных волеизъявлений, которое в отличие от односторонней сделки возможно только устно или письменно. Причем одна из сторон, должна выразить свою волю другой стороне обязательно словесно. В этой связи нельзя согласиться с авторами, допускающими возможность заключения договора конклюдентными действиями [7, с. 19; 9]. Следует отметить, что в судебной практике суды часто указывают, что договор заключен конклюдентными действиями. В частности, в постановлении Арбитражного Суда Центрального округа от 2 апреля 2015 г. № Ф10-487/2015 (дело № А68-1031/2014) сказано, что судами сделан правомерный вывод о том, что действия ООО «Геогаз» и ООО «Трансгаз» по выставлению счета и его оплате свидетельствуют о заключении сторонами договора поставки путем конклюдентных действий [20]. В этой ситуации вряд ли можно представить, что выставление счета и его оплата произведены сторонами без какой-либо предварительной устной договоренности. Поэтому невозможно представить достижение соглашения и определение его содержания без словесного выражения воли хотя бы одной из сторон, в частности только конклюдентными действиями или конклюдентными действиями и молчанием. Такие волеизъявления в литературе получили название косвенных [18, с. 20]. Их содержание, в отличие от прямых 
волеизъявлений (устного и письменного) не всегда можно определить однозначно.

Таким образом, гражданско-правовой договор может быть совершен только в устной или письменной форме, так что без словесного общения не может возникнуть соглашения как основообразующего элемента договора.

В свою очередь в письменной форме договор может быть заключен путем составления одного документа на материальном носителе (бумажного) либо электронного, подписанного сторонами, или обмена документами (письма, телеграммы, электронные сообщения и документы) (п. 2. ст. 434 ГК РФ). Причем в условиях, когда общение между сторонами все чаще происходит с использованием информационно-телекоммуникационной сети «Интернет», обмен электронными документами и электронными сообщениями получил наиболее широкое распространение при заключении договора, что создало определенные трудности в различии устной или письменной формы. Несмотря на это можно полностью согласиться с А.И. Савельевым, который считает, что «никакой иной формы договора (например, электронной) гражданское законодательство РФ не предусматривает» [21], а отдельные авторы рассматривают электронную форму договора как разновидность письменной формы [22].

Требования к форме договора установлены в гражданском законодательстве в нормах о форме сделок (ст.ст.158-165 ГК РФ), общих положениях о договоре (ст. 433 ГК РФ), отдельных видах обязательств и достаточно однозначно понимаются, как в научной литературе, так и в судебной практике. Общий законодательный подход к форме договора сводится к предоставлению сторонам возможности самостоятельно выбрать форму договорного соглашения, за исключением тех видов договоров, для которых несоблюдение простой письменной формы влечет их недействительность, если это прямо указанно в законе или в соглашении сторон (п. 2 ст. 162 ГК РФ). Если таких указаний нет, то заключая договор, стороны могут придать ему как устную, так и письменную форму. Причем в п. 1 ст. 161 ГК РФ установлены дополнительные требования, когда договор должен совершаться в письменной форме, но эти требования носят рекомендательный характер, так как отсутствие письменного договора в этих случаях не влечет его недействительность, а только затрудняет сторонам возможности по доказыванию факта заключенного договора. Этот факт может быть подтвержден только письменными и другими доказательствами, но не свидетельскими показаниями, что связано с их неоднозначностью и противоречивостью. В судебной практике факт заключенного договора между сторонами при отсутствии письменной формы, как правило, подтверждается документами, отражающими факты исполнения сторонами своих обязанностей по договору. Так факты перечисления денег в счет оплаты по договору подтверждаются платежными документами (выставление счета и его оплата) [23,24], выписками с банковских счетов [23, 25-28], передачей имущества - накладными и товарораспорядительными документами [29], выполнением работ - проектной сметной документацией на объем работ, актами о приемке работ [29]; другими документами, отражающими взаимную переписку, переговоры, товарный и денежный оборот [23, 31].

В этой связи можно утверждать, что право выбора сторонами формы договора является одной из составляющих основополагающего принципа договорного права - принципа свободы договора, хотя прямо и не установленного в ст. 421 ГК РФ, но встречающегося в других правопорядках [32, с. 86, 33].

Наличие в судебной практике достаточно большого количества споров, связанных с договором, заключенным устно, свидетельствует о том, что в коммерческом обороте для ее субъектов, по-прежнему важным остается простота и быстрота возникновения договорных отношений, несмотря на высокие риски неисполнения обязательств и трудности судебного доказывания. Устная форма договора, как правило, распространена в случае массового заключения договоров, в частности, розничная купля-продажа, бытовое обслуживание населения, но также может использоваться и предпринимателями, работающими продолжительное время и имеющими репутацию добросовестных партнеров. В основе волеизъявления сторон при заключении договора в устной форме лежит доверие между сторонами. При отсутствии доверия, а также, если договорные отношения между сторонами носят длящийся или сложный (смешанный договор) характер, то в современной практике стороны предпочитают письменную форму. Но даже наличие письменной формы не всегда гарантирует обязательное исполнение по договору и отсутствие судебных споров. В связи с этим, международные правовые акты вообще не устанавливают требования о наличии письменного договора в сфере международной торговли, так что любой договор может заключаться в устной форме и доказываться любыми средствами, включая свидетельские показания [34].

Жизнь современного общества уже не мыслима без использования компьютерных технологий, мобильных средств связи и сети «Интернет», которые коренным образом изменили способ взаимодействия субъектов, практически вытеснив бумажную форму общения. В настоящее время большая часть договоров между гражданами и субъектам предпринимательской деятельно- 
сти заключаются путем электронного взаимодействия сторон. В употребление прочно вошли такие термины как электронный билет, электронная накладная, электронный полис.

Информационные технологии существенно повлияли и на процесс оформления договорных отношений, без чего договор не может быть доступен для восприятия другими лицами, в том числе и судом. Использование обмена электронными документами и сообщениями в сети «Интернет», с одной стороны расширило возможности субъектов по доказыванию наличия договорных отношений при отсутствии письменной формы договора, ввиду невозможности использовать свидетельские показания. С другой стороны, усложнило вопрос об отграничении устного договора, от договора, совершенного в письменной форме, что необходимо в случае, когда законом под страхом недействительности для договоров отдельных видов предписывается обязательная письменная форма (п. 2 Ст. 162 ГК РФ). К таким договорам, в частности, относятся договоры о залоге (абз. 3 п. 3 ст. 339 ГК РФ), поручительстве (ст. 362 ГК РФ), предварительный договор (п. 2 ст. 429 ГК РФ), договоры продажи недвижимости и предприятия (абз. 2 ст. 550 и п. 2 ст. 560 ГК РФ), аренды здания или сооружения и предприятия (абз. 2 п. 1 ст. 651 и п. 3 ст. 658 ГК РФ), кредитный договор (абз. 2 ст. 820 ГК РФ), договор банковского вклада (п. 2 ст. 836 ГК РФ).

Анализ п. 2 ст. 160, п. ст. 434 и п. 4 ст. 11 Федерального закона от 27 июля 2006 г. N149-Ф3 «Об информации, информационных технологиях и о защите информации» [35] показывает, что договор между сторонами при их взаимодействии с помощью электронных средств связи будет считаться заключенным в письменной форме, когда он составлен в виде одного электронного документа, подписанного сторонами электронной подписью, либо обмена электронными документами, каждое из которых подписано электронной подписью [36] или иным аналогом собственноручной подписи лица, отправившего документ. В качестве дополнительных критериев для признания письменной формы договора, совершенного электронным способом, закон устанавливает требование о возможности воспроизведения на материальном носителе в неизменном виде содержания договора (как минимум наличие существенных условий) и наличие подписи электронного документа, способ создания которой позволяет достоверно установить лицо, выразившее волю на заключение договора. Вместо подписи электронного документа, стороны до заключения договора в отдельном соглашении могут предусмотреть специальный способ для достоверного определения участников такого договора.
Таким образом, установленные в законах требования о соблюдении письменной формы договора, заключаемого с помощью электронных средств связи, не создает определенности правового регулирования и порождает ряд вопросов практического характера.

Учитывая, что даже электронная подпись не всегда может свидетельствовать о подлинности документа и подписании его лицом, которому она выдана, т.к. даже самую защищенную электронную подпись гарантированно можно «взломать» и фальсифицировать удостоверенный ею документ [37], то что из себя должна представлять иная подпись (аналог собственноручной подписи) на электронном документе и о какой достоверности документа она может свидетельствовать. Можно ли, например, в качестве аналога собственноручной подписи лица, считать чернильную подпись на отправленной скан-копии оригинала документа или какой-либо символ, знак, имя отправителя в конце электронного документа. Будет ли обмен электронными документами, в конце которых стоит символ, знак, имя отправителя, либо обмен скан-копиями оригиналов документов с живыми (чернильными) подписями каждой из сторон подтверждать наличие письменной формы договора. Если обмен такими документами установлен в соглашении сторон, то в какой форме оно должно быть заключено. Вряд ли можно однозначно ответить на эти вопросы. Хотя, в одном из рассмотренных дел Судебная коллегия по гражданским делам Верховного Суда РФ полагает, что договор может быть заключен путем обмена скан-копиями подписанных сторонами экземпляров договора. При этом нет необходимости отдельно подписывать электронные сообщения электронной подписью [38]. Аналогичную позицию занял суд и в другом деле, указав, что «представленный в материалы дела электронный образ договора от 12.09.2017 N21-09-иа/17, созданный путем сканирования, а также приложение к договору (перечень оборудования) и иную электронную переписку сторон по поводу работ по оценке имущества, суды пришли к выводу о заключенности данного договора посредством обмена электронными образами этого договора и сообщениями между сторонами» [39].

Что касается использования для подписания электронного документа электронной подписи, то в судебной практике имеются разные подходы к этому вопросу. Так в одном случае, подписание договора простой электронной подписью (посредством sms, направленного на телефон гражданину) признается судом равнозначным документам на бумажном носителе подписанным собственноручной подписью, и может служить доказательством в суде [40]. В другой аналогичной ситуации суд наоборот указал, что «подача заявки через «Интернет» на получение кредита и введение кода, на- 
правленного заявителю на телефон посредством sms, не свидетельствует о заключении кредитного договора именно с тем гражданином, чьи паспортные данные указаны в заявке» [41]. В третьей ситуации, суд сделал вывод, что «порядок использования электронной подписи при документообороте сторон, заключении гражданско-правых сделок допускается только при наличии взаимного соглашения сторон и при его отсутствии не свидетельствует о заключенности договора [42]. Вся иная переписка между сторонами затрудняющая определение подписей сторон и полномочия лиц, которые вели переписку от имени сторон, как указано в судебных постановлениях, не может рассматриваться в качестве допустимого доказательства наличия заключенного договора, так как не свидетельствует о реальности хозяйственных операций и не означает, что между сторонами достигнуто какое- либо соглашение [43]. Однако, как правильно замечено Е.А. Наховой, отсутствие соглашения об обмене электронными документами между сторонами переписки, как и отсутствие электронной цифровой подписи в отправляемых и получаемых документах, не препятствует использованию соответствующих документов и материалов в качестве доказательств [44], и подлежит оценке наряду с другими, в том числе косвенными, доказательствами в их взаимосвязи и совокупности [45]. Следовательно, в этих случаях, если для заключаемого путем электронного взаимодействия сторон договора законом не установлена обязательная письменная форма, такой договор следует считать заключенным в устной форме. Факт заключения может доказываться в суде любыми доказательствами, за исключением свидетельских показаний, в том числе информацией, созданной в результате электронного общения сторон, путем обмена электронными сообщениями в сети «Интернет».

Общение граждан, в том числе и при осуществлении предпринимательской деятельности, в сети «Интернет» происходит путем переписки электронными сообщениями по электронной почте, в мобильных приложениях (WhatsApp, Viber, Telegram и др.), в социальных сетях, на сайтах продавцов при дистанционной продаже товаров. Причем по своему содержанию электронные сообщения могут включать информацию как о заключении договора, так и выполнении действий, направленных на его исполнение. Несмотря на то, что эти сообщения имеют письменную форму, договор заключенный и исполненный в ходе обмена такими сообщениями следует считать устным договором. По этому поводу в литературе имеются противоречивые суждения. Так, Д.П. Стригунова вообще не может определиться с формой электронных сообщений, указывая что «Такие сообщения не могут признаваться устными, поскольку по своей сути являются невербальными, однако признаваться письменными с соответствующим им юри- дическим значением они, как правило, также не могут, поскольку в них обычно отсутствует подпись оферента» [22]. В свою очередь А.И. Савельев вообще отвергает устную форму договора в таких случаях, утверждая «принимая во внимание экзотический характер устной формы при заключении договоров посредством Интернета, ...... основной формой договора в сфере электронной коммерции остается простая письменная форма» [21]. Возражая данным авторам, следует сказать, что письменная форма договора при электронном взаимодействии сторон будет считаться соблюденной только в случае обмена электронными документами, подписанными электронной подписью или аналогом собственноручной подписи сторон, позволяющей определить лицо, выразившее волю при его заключении. При отсутствии в электронном документе электронной или иной подписи, его нельзя рассматривать как документ, достоверно выражающий волю стороны на заключение договора, а следует отнести к электронным сообщениям сторон. Сами электронные сообщения выражены в письменной форме, но форму договора, заключаемого в ходе обмена такими сообщениями, следует считать устной, так как отсутствуют документы, подписанные сторонами. А сами электронные сообщения сторон следует отнести к документам (письменным доказательствам), подтверждающим как заключение договора, так и исполнение сторонами принятых обязательств. При условии, что будет достоверно установлено, что они сформированы и отправлены сторонами по договору, по аналогии электронного документа В договоре розничной купли-продажи (ст. 493 ГК РФ) или расписки заемщика, удостоверяющего передачу денежной суммы (п. 2 ст. 808 ГК РФ).

Проникновение информационных технологий во все сферы современного общества и расширение электронного взаимодействия субъектов общественных отношений не могут трансформировать сами общественные отношения, где они применяются, так как являются всего лишь инструментом, повышающим эффективность в достижении результата этих отношений. Как справедливо отметил А.Х. Хисамов, изучая интеграцию информационных технологий в гражданский процесс, «внедрение элементов или технологий, характеризующих «информационность» или «электронность» правосудия, не изменяет сущности правосудия как правоприменительной деятельности, в результате которой реализуется судебная власть» [46]. Применительно к гражданско-правовым отношениям и, в частности к договорным, использование электронных (цифровых) технологий также не меняет сущности этих правоотношений. Поэтому не может быть никаких электронных (цифровых) договорных отношений, как и электронной (цифровой) формы гражданско-правового договора, так как эти отношения возникают по поводу переме- 
щения материальных благ от одних лиц к другим, даже если эти блага выражены в каких-то цифровых единицах («виртуальные валюты», в частности, Биткойн). Так при заключении договора путем обмена электронными документами, подписанными электронной подписью или путем переписки электронными сообщениями в сети «Интернет», содержание волеизъявления каждой из сторон выражается словесно в письменной форме, но в машиночитаемом виде, так что ее восприятие другими лицами возможно только с помощью технических устройств. Форма заключаемого договора будет письменной только в случае обмена электронными документами, подписанными электронной подписью или ее аналогом.

\section{ЛИТЕРАТУРА}

1. Советское гражданское право: В 2 т. / Отв. ред. В.П. Грибанов, С.М. Корнеев. М., 1979. Т. 1. 552 с.

2. Абрамова Е.Н. К вопросу о понятии формы сделки // Нотариус. 2015. № 6. С. 3-7; № 7. С. 3-7.

3. Данилов И.А. Требования, предъявляемые законом к форме сделок // Юридический мир. 2010. № 7. С. 13-17.

4. Евсеев Е.Ф. Устная сделка // Законодательство и экономика. 2014. N7. С. 25-31.

5. Епифанова В.В. Форма сделки: теория и практика реализации в гражданском законодательстве: дис. ... канд. юрид. наук: 12.00 .03 / Епифанова Валерия Владимировна; [Место защиты: Юж. федер. ун-т].— Ростов-на-Дону, 2009. 178 с.

6. Мельников В.С. Форма сделок // Юридический мир. 2012. N4. С. 20-22.

7. Никифоров В.С. Форма сделок в российском гражданском праве: автореферат дис. ... кандидата юридических наук: 12.00 .03 / Никифоров Виктор Сергеевич; [Место защиты: Рос. гос. ин-т интеллектуал. собственности Роспатента]. — Рязань, 2009. 25 с.

8. Семенов М. Письменная форма сделок в российском гражданском праве // Хозяйство и право.— М., 2003, № 2. - C. 67-72;

9. Татаркина К.П. Форма сделок в гражданском праве России: Монография. Томск: Томский государственный университет систем управления и радиоэлектроники, 2012. 264 с.

10. Матвеев И.И. Юридическое значение формы сделки и ответственность за ее нарушение // Хозяйство и право. 2001. № 12. С. 90-97.

11. Покровский Б.В. Основные проблемы гражданского права. М.: Статут, 1998. 353 с.

12. Обзор судебной практики Верховного Суда Чувашской Республики по гражданским делам за II квартал 2013 года. // Документ опубликован не был. Доступ из справ.-правовой системы «КонсультантПлюс».

13. Постановление ФАС Волго-Вятского округа от 17.10.2011 по делу № А11-9013/2010 // Документ опубликован не был. Доступ из справ.-правовой системы «КонсультантПлюс».

14. Постановление Арбитражного суда Московского округа от 22.02.2018 № Ф05-745/2018 по делу № А41-37220/2017;

15. Постановление Арбитражного суда Центрального округа от 12 сентября 2017 г. № Ф10-2700/17 по делу № А08-3247/2016 // Документ опубликован не был. Доступ из справ.-правовой системы «КонсультантПлюс».

16. Постановление Арбитражного суда Уральского округа от 20 марта 2017 г. № Ф09-1060/17 по делу № А07-10868/2016 // Документ опубликован не был. Доступ из справ.-правовой системы «КонсультантПлюс».

17. Постановление Арбитражного суда Северо-Западного округа от 27 декабря 2016 г. № Ф07-11508/16 по делу № А66-264/2016 // Документ опубликован не был. Доступ из справ.-правовой системы «КонсультантПлюс».

18. Новицкий И.Б. Сделки. Исковая давность. М.: Госюриздат, 1954. 416 с.

19. Хейфец Ф.С. Недействительность сделок по российскому гражданскому праву. М.: Юрайт, 1999. 144 с.;

20. Постановление Арбитражного Суда Центрального округа от 2 апреля 2015 г. № Ф10-487/2015 по делу № А68-1031/2014 // Документ опубликован не был. Доступ из справ.-правовой системы «КонсультантПлюс».

21. Савельев А.И. Электронная коммерция в России и за рубежом: правовое регулирование. 2-е изд. М.: Статут, 2016. 640 с. // Доступ из справ.-правовой системы «КонсультантПлюс».

22. Стригунова Д.П. Некоторые аспекты заключения международного коммерческого договора в электронной форме // Юрист. 2017. № 16. С. $35-39$.

23. 0бзор судебной практики Верховного Суда РФ (утв. Президиумом Верховного Суда Российской Федерации 25 ноября 2015 г. (вопрос 10) // Документ опубликован не был. Доступ из справ.-правовой системы «КонсультантПлюс».

24. Постановление Арбитражного Суда Центрального округа от 2 апреля 2015 г. N Ф10-487/2015 по делу N A68-1031/2014 // Документ опубликован не был. Доступ из справ.-правовой системы «КонсультантПлюс».

25. Постановление Арбитражного суда Московского округа от 19 января 2017 г. N Ф05-20774/16 по делу N А40-74429/2016 // Документ опубликован не был. Доступ из справ.-правовой системы «КонсультантПлюс».

26. Постановление Арбитражного суда Московского округа от 22.02.2018 № Ф05-745/2018 по делу № А41-37220/2017 // Документ опубликован не был. Доступ из справ.-правовой системы «КонсультантПлюс».

27. Постановление Арбитражного суда Центрального округа от 12 сентября 2017 г. № Ф10-2700/17 по делу № А08-3247/2016// Документ опубликован не был. Доступ из справ.-правовой системы «КонсультантПлюс».

28. Постановление Арбитражного суда Московского округа от 22.02.2018 № Ф05-745/2018 по делу № А41-37220/2017 // Документ опубликован не был. Доступ из справ.-правовой системы «КонсультантПлюс». 
29. Постановление Арбитражного суда Московского округа от 22.02.2018 № Ф05-745/2018 по делу № А41-37220/2017 // Документ опубликован не был. Доступ из справ.-правовой системы «КонсультантПлюс».

30. Постановление Арбитражного суда Центрального округа от 12 сентября 2017 г. № Ф10-2700/17 по делу № А08-3247/2016// Документ опубликован не был. Доступ из справ.-правовой системы «КонсультантПлюс».

31. Постановление Арбитражного суда Московского округа от 22.02.2018 № Ф05-745/2018 по делу № А41-37220/2017 // Документ опубликован не был. Доступ из справ.-правовой системы «КонсультантПлюс».

32. Осакве К. Свобода договора в англо-американском праве: понятие, сущность и ограничения // Журнал российского права. 2006. № 7. С. 84-91, № 8. C. 131-143.

33. Стригунова Д.П. Принцип свободы договора: российский и зарубежный опыт // Гражданское право. 2018. N3. С. 10-13.

34. Конвенции 0ОН «0 договорах международной купли-продажи товаров» (заключена в Вене 11.04.1980, Вступила в силу для СССР с 01.09.1991) ст. 11// Вестник ВАС РФ. 1994. № 1

35. Федеральный закон от 27 июля 2006 г. 149-Ф3 «06 информации, информационных технологиях и 0 защите информации» // СЗ РФ. 2006. № 31 (часть I), ст. 3448

36. Федеральный закон от 6 апреля 2011 г. N63-Ф3 «06 электронной подписи» // С3 РФ. 2011. № 15, ст. 2036.

37. Лисаченко А.В. Идентификация субъектов гражданских правоотношений: новые проблемы и некоторые решения // Российский юридический журнал. 2019. № 5. С. 91-99.

38. Будылин С.Л. Заключение договора путем обмена скан-копиями, или Дело о сосновом срубе. Комментарий к Определению Судебной коллегии по гражданским делам ВС РФ от 19.09.2017 N78-КГ17-56 // Вестник экономического правосудия Российской Федерации. 2017. N12. C. 10-22.

39. Постановление Арбитражного суда Уральского округа от 14 января 2019 г. N Ф09-8370/18 по делу N A60-6636/2018 // Документ опубликован не был. Доступ из справ.-правовой системы «КонсультантПлюс».

40. Определение СК по гражданским делам Третьего кассационного суда общей юрисдикции от 07 июня 2021 г. по делу N8Г-7958/2021[88-8796/2021] // Документ опубликован не был. Доступ из справ.-правовой системы «КонсультантПлюс».

41. Определение Третьего кассационного суда общей юрисдикции от 23 декабря 2020 г. по делу N8Г-21905/2020[88-20192/2020] // Документ опубликован не был. Доступ из справ.-правовой системы «КонсультантПлюс».

42. Постановление Арбитражного суда Московского округа от 13 июля 2017 г. N Ф05-9492/17 по делу N A40-78415/2016; Постановление Арбитражного суда Западно-Сибирского округа от 15 июня 2018 г. N Ф04-2087/18 по делу N A45-20155/2016 // Документ опубликован не был. Доступ из справ.-правовой системы «КонсультантПлюс».

43. Постановление Арбитражного суда Московского округа от 21 ноября 2019 г. N Ф05-20076/19 по делу N A41-16969/2019; Постановление Арбитражного суда Московского округа от 27 августа 2018 г. N Ф05-11749/18 по делу N A41-84219/2017 // Документ опубликован не был. Доступ из справ.-правовой системы «КонсультантПлюс».

44. Нахова Е.А. Проблемы применения электронных доказательств в цивилистическом процессе и административном судопроизводстве // Закон. 2018. № 4. C. 81-90.

45. Постановление Арбитражного суда Дальневосточного округа от 21 августа 2020 г. N Ф03-2057/20 по делу N A73-8610/2018 // Документ опубликован не был. Доступ из справ.-правовой системы «КонсультантПлюс».

46. Хисамов А.Х. Тенденции интеграции информационных технологий в цивилистический процесс // Вестник гражданского процесса. 2018. № 1. С. 229247.

(c) Баринов Андрей Викторович ( barinov-vlad@inbox.ru ),

Кузнецова Наталья Владимировна ( kuznezova-1963@mail.ru ), Рябова Ольга Алексеевна ( frau.lelya2012@yandex.ru ).

Журнал «Современная наука: актуальные проблемы теории и практики» 